\title{
Relationship between aerobic fitness, blood pressure and life satisfaction
}

Authors' Contribution: A Study Design

B Data Collection

C Statistical Analysis

D Data Interpretation

E Manuscript Preparation

F Literature Search

G Funds Collection

\author{
Attila Szabo ${ }^{\text {ABCDEF, }}$ Tamás Bőhm ${ }^{2}$ BDEF, Ferenc Köteles ${ }^{1}$ ACEF \\ ${ }^{1}$ Institute of Health Promotion and Sport Sciences and Institute of Psychology, \\ ELTE Eötvös Loránd University, Budapest, Hungary \\ 2 Department of Anaesthesiology and Intensive Therapy, \\ Semmelweis University, Budapest, Hungary
}

\section{abstract}

Background: The aim of this work was to examine the extent to which cardiorespiratory fitness, blood pressure, and optimism/pessimism predict adults' satisfaction with life.

Material and methods: Sixty-eight adults seeking cardiovascular health screening in a private clinic were tested. Participants' blood pressure, optimism/pessimism, and satisfaction with life were recorded. The YMCA cycle ergometer test was used for estimating participants' aerobic fitness (VO2 max). Based on 140/90 mm $\mathrm{Hg}$ blood pressure cut-off value, participants were classified into two groups.

Results: A bootstrapped hierarchical multivariate regression analysis revealed that VO2 max, systolic blood pressure, optimism, and pessimism jointly accounted for $46 \%$ of the variance $\left(R^{2}=0.501, R^{2}\right.$ adjusted $=0.462$ ) in life satisfaction. Furthermore, a bootstrapped multivariate analysis of covariance indicated that Stage 2 hypertensives reported lower life satisfaction $(p=0.007)$ than the others with lower blood pressure readings.

Conclusions: This study is the first to reveal that almost half of the total variance in life satisfaction is accounted by cardiorespiratory fitness, systolic blood pressure, optimism, and pessimism. The present work also shows that individuals in Stage 2 hypertension are less satisfied with their lives than individuals with lower blood pressure values. These preliminary findings should stimulate both epidemiological and longitudinal research in the area.

Key words: adult, aerobic, blood pressure, positive attitude, VO2 max, YMCA test.

\section{article details}

Article statistics:

Full-text PDF:

Copyright

Indexation:

Conflict of interests: Corresponding author:

Open Access License:
Word count: 5,912; Tables: 3; Figures: 0; References: 50

Received: October 2019; Accepted: April 2020; Published: June 2020

http://www.balticsportscience.com

(c) Gdansk University of Physical Education and Sport, Poland

Celdes, Clarivate Analytics Emerging Sources Citation Index (ESCI), CNKI Scholar (China National Knowledge Infrastructure), CNPIEC, De Gruyter - IBR (International Bibliography of Reviews of Scholarly Literature in the Humanities and Social Sciences), De Gruyter - IBZ (International Bibliography of Periodical Literature in the Humanities and Social Sciences), DOAJ, EBSCO - Central \& Eastern European Academic Source, EBSCO - SPORTDiscus, EBSCO Discovery Service, Google Scholar, Index Copernicus, J-Gate, Naviga (Softweco, Primo Central (ExLibris), ProQuest - Family Health, ProQuest - Health \& Medical Complete, ProQuest - Illustrata: Health Sciences, ProQuest - Nursing \& Allied Health Source, Summon (Serials Solutions/ProQuest, TDOne (TDNet), Ulrich's Periodicals Directory/ulrichsweb, WorldCat (OCLC)

This research received no specific grant from any funding agency in the public, commercial, or not-for-profit sectors. Authors have declared that no competing interest exists.

Prof. Attila Szabo, Ph.D., D.Sc., (ORCID: https://orcid.org/0000-0003-2788-4304) Professor of Psychology, Institute of Health Promotion and Sport Sciences, Faculty of Education and Psychology, ELTE Eötvös Loránd University, 1117 Budapest, Bogdánfy u. 10/B, Hungary. E-mail: szabo.attila@ppk.elte.hu.

This is an open access article distributed under the terms of the Creative Commons Attribution-Non-commercial 4.0 International (http://creativecommons.org/licenses/by-nc/4.0/), which permits use, distribution, and reproduction in any medium, provided the original work is properly cited, the use is non-commercial and is otherwise in compliance with the license. 


\section{INTRODUCTION}

Research has shown that life satisfaction predicts self-perceived health, physical health, long-term health conditions [1] and even mortality [2]. Therefore, it may not be surprising that aerobic fitness, which is closely related to cardiovascular health and blood pressure status [3], may also be linked to life satisfaction [4]. Life satisfaction was defined as the subjective (cognitive) aspect of well-being and refers to individuals' overall appraisal of the quality of their lives [5]. Higher life satisfaction was associated with optimism [6]. Optimism and pessimism appear to be closely connected to life satisfaction in opposite directions [7]. Accordingly, life satisfaction could be associated with cardiovascular measures such as aerobic fitness and blood pressure, as well as optimism and pessimism. The primary objective of this preliminary investigation was to determine the extent to which these factors predict life satisfaction.

\section{OPTIMISM AND CARDIOVASCULAR HEALTH}

Positive psychological orientation appears to be connected to cardiovascular health. Among several factors, positive mental orientation is reflected via optimism, which is a general tendency to expect positive future events and can be conceptualized as dispositional to anticipate good things to happen, or as attributional via causal association with past positive experiences [8]. Research suggests that optimism may be related to a lower risk of coronary heart disease $[9,10]$. One earlier study found a positive relationship between optimism and the rate of recovery from bypass surgery [11]. Another study showed that optimism predicted health outcomes after acute coronary syndrome [12]. Research also suggests that optimism could be associated with a lower risk of cardiovascular mortality [13-15]. Finally, a literature review concludes that optimism is consistently associated with cardiovascular health [16]. Therefore, an association between optimism and cardiovascular health, in general, seems to be supported by the extant literature.

\section{PESSIMISM AND CARDIOVASCULAR HEALTH INDICES}

In contrast to the results of the studies linking higher optimism to better cardiovascular health, a study of young Finnish adults revealed that low pessimism was more closely related to cardiovascular health than high optimism [17]. Similarly, another study showed that lower pessimism, rather than higher optimism, was associated with a lower risk of stroke [18]. Earlier, Mahler and Kulik [19] reported that both optimism and pessimism could predict recovery from bypass surgery, but lower pessimism was a stronger predictor of recovery than higher optimism. Hence, pessimism reflects a general tendency of expecting future negative events [20] and, apparently, has a significant influence on the outcome of those events. It is an inverse dimension of the positive mental attitudes, which strongly suggests that a two-dimensional approach to studying optimism and pessimism in the context of health outcomes seems to be justified, which was also confirmed in earlier studies [21].

\section{OPTIMISM AND PESSIMISM AND LIFE SATISFACTION}

As reported above, optimism is related to greater satisfaction with life in young adults [22]. Later, Chang and Sanna [23] found a positive relationship between optimism and satisfaction with life, whereas pessimism was negatively related to the latter in middle-aged adults. In another investigation examining psychology 
students, a positive association was disclosed between optimism and satisfaction with life [24]. Examining a comparable sample, Bailey et al. [21] revealed that pessimism was an inverse predictor of satisfaction with life, but in their second inquiry, testing middle-aged adults, optimism was more strongly related to life-satisfaction than pessimism. These preliminary findings were supported by a more recent work in which optimism was positively, whereas pessimism was negatively associated with the reported satisfaction with life in a sample of participants with a relatively wide age-range [7]. Therefore, based on the limited number of studies connecting both optimism and pessimism with life satisfaction, it appears that these mental attitudes play an important role in how one is satisfied with life in general.

\section{LIFE SATISFACTION AND CARDIOVASCULAR HEALTH INDICES}

Only a few inquiries have examined the relationship between satisfaction with life and cardiovascular health. One of them showed that satisfaction with life was associated with a reduced risk of coronary heart disease [25], and another revealed an association between life satisfaction and a risk of cardiovascular events [26]. However, basic routinely screened indices of cardiovascular health, such as blood pressure or cardiorespiratory fitness, have seldom attracted researchers' attention. In an exhaustive search of literature, we could only find one study in which a relationship between satisfaction with life and blood pressure was investigated [27]. This study showed that being male, low satisfaction with life and increased age were statistically significant predictors of high blood pressure. However, Romero Martinez and her colleagues examined adolescents and, therefore, the relevance of their findings might not be generalized to adults. Nevertheless, considering the limited evidence linking cardiovascular health with satisfaction with life, the findings reported by these researchers merit further investigation in adults. Currently, indirect evidence showing an inverse association between blood pressure with marital life satisfaction in adults [28] also supports the idea that satisfaction with life, in general, may be connected to a healthier blood pressure profile. Overall, while only one study examined the link between blood pressure and life satisfaction, the connection between cardiovascular health (of which blood pressure and aerobic fitness are two indices) and psychological states, including life-satisfaction, is relatively well-established [29, 30].

\section{AEROBIC (CARDIORESPIRATORY) FITNESS AND LIFE SATISFACTION}

A recent study reported that perceived (subjective) cardiorespiratory, or aerobic, fitness was positively associated with satisfaction with life in adolescents [31]. The cross-sectional findings are corroborated by two earlier studies in which the objectively estimated level of aerobic fitness was positively related to life satisfaction in young children and adolescents [4, 32]. These studies examined children and adolescents, while studies with adults appear to be lacking. One exception is a relatively recent work examining a small number $(n=28)$ of university students that adopted the step test for estimating the aerobic fitness of the participants, which turned out to be unrelated to their life satisfaction [33]. To the best of our knowledge, the connection between cardiorespiratory fitness and satisfaction with life was not examined to date in older, middle aged adults. Examining this population, however, seems to be warranted because cardiovascular fitness decreases with age [34]. 


\section{MATERIALS AND METHODS}

\section{PARTICIPANTS}

Adults presenting themselves for a cardiovascular health screening at a large private medical centre in the capital area were invited to take part in the study. Participation was voluntary and bound to signing an informed consent form. The research was conducted in accord with the Helsinki Declaration [36] and with the permission of the Research Ethics Committee of the Faculty of Education and Psychology of ELTE Eötvös Loránd University, Budapest. The required sample size was determined a priori by using the G* Power version 3.1.9.2 software [37]. The expected squared multiple correlation coefficient was estimated to be at least 0.25 based on past reports (after data collection, it turned out be 0.50 in the current study), and therefore this value was used to calculate the effect size $\left(f^{2}\right)$, which resulted in an $f^{2}=0.33$. Using this value, four predictors, error $\alpha=0.05$, and power $1-\beta=0.95$, the total required sample size was 61 . The final sample size was 68 , which exceeded the minimum required sample size. Participants' characteristics are presented in Table 1.

Table 1. Participants' description

\begin{tabular}{lcc} 
Measures & Men & Women \\
\hline Number of participants $(\mathrm{n})$ & 29 & 39 \\
Age $(M \pm \mathrm{SD})$ & $41.69 \pm 11.42$ & $39.77 \pm 11.60$ \\
Height $(\mathrm{cm})^{*}$ & $180.90 \pm 8.00$ & $168.56 \pm 6.87$ \\
Weight $(\mathrm{kg})^{*}$ & $87.03 \pm 11.56$ & $67.74 \pm 15.02$ \\
Married or in relationship (n) & $28 / 29(97 \%)$ & $31 / 39(79 \%)$ \\
Works (n) & $28 / 29(97 \%)$ & $39 / 39(100 \%)$ \\
University graduate (n) & $18 / 29(62 \%)$ & $31 / 39(79 \%)$ \\
Smokes or used to smoke (n) & $12 / 29(41 \%)$ & $20 / 39(51 \%)$ \\
Resting heart rate (bpm, M $\pm \mathrm{SD})$ & $70.52 \pm 12.12$ & $70.41 \pm 15.76$ \\
VO2 max (ml/kg/min, M \pm SD) & $35.65 \pm 10.78$ & $34.47 \pm 11.75$ \\
Systolic blood pressure (M \pm SD)* & $152.03 \pm 15.27$ & $141.21 \pm 19.66$ \\
Diastolic blood pressure (M \pm SD) & $90.28 \pm 7.29$ & $88.59 \pm 11.37$ \\
Mean arterial pressure (M \pm SD) & $110.86 \pm 8.74$ & $106.13 \pm 13.55$ \\
Optimism (M \pm SD) & $11.55 \pm 2.29$ & $11.56 \pm 2.83$ \\
Pessimism (M \pm SD)* & $7.00 \pm 2.54$ & $5.59 \pm 2.34$ \\
Satisfaction with life (M \pm SD) & $25.21 \pm 4.41$ & $26.21 \pm 6.43$ \\
\hline
\end{tabular}

\section{METHODS}

Cardiorespiratory fitness. Aerobic fitness $\left(\mathrm{VO}_{2} \max \right)$ was estimated with the YMCA submaximal cycle ergometer test [38] using an 'Ergoline, ergoselect 100' ergometer, manufactured by ergoline GmbH, Bitz, Germany. Heart rate data were obtained with a Marquette (227 498 02-A V4.1) CardioSys ECG System manufactured by Marquette Hellige $\mathrm{GmbH}$, Freiburg, Germany.

Blood pressure. Systolic and diastolic blood pressure were measured at rest with a 'Microlife BP A100 Plus' automatic blood pressure monitor manufactured by Microlife AG Swiss Corporation. This device uses the same blood pressure measuring technology as the 'BP 3BTO-A' model tested in accord with the British Hypertension Society (BHS) protocol [39]. Accordingly, Microlife obtained grade 'A' for both systolic and diastolic pressure according to the BHS protocol. 
The mean differences $( \pm S D)$ between the observers and the tested unit were -1.6 (7.7) $\mathrm{mmHg}$ and -2.1 (6.3) $\mathrm{mmHg}$ for systolic and diastolic blood pressure, respectively. Hence, this unit also fulfils the criterion set by the Association for the Advancement of Medical Instrumentation [39].

Satisfaction with Life. The Satisfaction with Life Scale (SWLS) [40] was adopted to measure general life satisfaction. The original SWLS has 5 items, which are rated on a 7-point Likert scale ranging from strongly disagree to strongly agree. A sample item of the SWLS is: 'In most ways my life is close to my ideal'. The internal reliability of the scale was good (Cronbach $\alpha=0.79-0.89$ ); its test-retest reliability, examined in several periods from one month to four years, ranged between 0.50 and 0.84 [41, 42]. In this research, we used the psychometrically validated Hungarian version of the SWLS [43] with a reported internal reliability of 0.84 . The internal reliability of the instrument in the current work was identical to that of the validated version (i.e., $\alpha=0.84$ ).

Optimism and pessimism. The Hungarian version [44] (2010) of the revised Life Orientation Test (LOT-R) [45] was adopted to measure optimism and pessimism. The scale consists of 10 items. Three items assess optimism, another three items measure pessimism and there are four filler items. A sample item for optimism is: 'In uncertain times, I usually expect the best' and a sample item for pessimism is: 'If something can go wrong for me, it will'. Respondents are requested to indicate the extent to which they agree or disagree with the items on a 5-point Likert scale ranging from strongly agree to strongly disagree. It should be noted that he LOT-R was originally developed to assess optimism as a unidimensional construct, with optimism and pessimism being the bipolar opposites [20]. However, later it was demonstrated that optimism and pessimism of the LOT-R reflect two independent constructs [46]. The psychometric properties of the twodimensional LOT-R are robust [46]. Its internal reliability, based on a large sample ( $\mathrm{n}=46,133$ ), was 0.71 for optimism and 0.68 for pessimism [46]. The internal reliability of the Hungarian version was reported to range between Cronbach's alpha 0.77 and 0.81 [44]. In the current sample, the internal reliability of the scale was 0.74 for optimism and 0.61 for pessimism.

\section{PROCEDURE}

After giving written consent for taking part in the current study, participants answered the demographic questions and completed the SWLS and the LOT-R in a quiet waiting room. Subsequently, their resting heart rate and blood pressure were recorded according to usual standard method [47]. Next, participants were invited to perform the YMCA submaximal cycle ergometer test [38]. Before the test, they were screened for taking any medications, injuries or musculoskeletal limitations, actual health status, and the time of the last meal. The purpose and the method of testing was explained. After measuring height and weight, participants were told that the test will last until their heart rate slightly exceeds $75 \%$ of the age predicted maximum heart rate, that the test would be stopped if they feel faint, dizzy, or short of breath, and they were assured that they are free to stop test at any time for any reason. Participants started the test by riding the ergometer at 50 revolutions per minute (rpm) which was increased at two-minute intervals until the target heart rate was reached, or the test had to be terminated for muscular fatigue. Heart rate and workload (watts) were recorded at each stage, before any increase in workload. The YMCA test was reported to yield a reliable estimate of the $\mathrm{VO}_{2}$ max when compared to the treadmill tests using direct measurements [38]. 
In the current test, participants' $\mathrm{VO}_{2}$ max was calculated from the last and preceding the last completed stage.

\section{RESULTS}

Initial correlation analyses indicated that satisfaction with life correlated positively with the estimated $\mathrm{VO}_{2} \max \left(r=0.25, r^{2}=0.063, p=0.04\right)$ and optimism ( $\left.r=0.56, r^{2}=0.313, p<0.001\right)$, while being reversely related to the systolic blood pressure $\left(r=-.25, r^{2}=0.063, p=0.04\right)$ and pessimism $\left(r=-.52, r^{2}=0.270, p<0.001\right)$. Statistically no significant correlation was observed between the diastolic blood pressure and satisfaction with life. Based on these relationships, a bootstrapped hierarchical linear multiple regression, using the enter method, was calculated to determine the extent to which the estimated $\mathrm{VO}^{2}$ max, systolic blood pressure, optimism, and pessimism could predict satisfaction with life. Considering gender differences in pessimism and systolic blood pressure (Table 1), gender was also included in the analysis.

This test resulted in a statistically significant regression equation $(F[5,60]$ $\left.=12.18, p<0.001, R=0.710, R^{2}=0.504, R^{2 \text { adjusted }}=0.462\right)$. The test of the standardized residuals confirmed that the data contained no outliers (Std. Residual Min = -2.37, and Std. Residual Max = 2.57). Further tests were performed to determine if the data met the assumption of collinearity. Their results confirmed that multicollinearity was not a concern in the data (gender: tolerance $=0.92$, Variance Inflation Factor $(V I F)=1.22 ; \mathrm{VO}_{2}$ max: tolerance $=0.91, \mathrm{VIF}=1.10$; systolic blood pressure: tolerance $=0.83, \mathrm{VIF}$ $=1.21$; optimism: tolerance $=0.78, \mathrm{VIF}=1.28$; and pessimism: tolerance $=$ $0.72, V I F=1.40$ ). The data also met the assumption of independent errors (Durbin-Watson $=1.873)$ and the assumption of non-zero variances $\left(s^{2}>0.00\right.$ for all predictors). Apart from gender, all predictors, contributed statistically significantly to the model (Table 2).

Table 2. Regression model coefficients

\begin{tabular}{|c|c|c|c|c|c|c|c|}
\hline \multirow{2}{*}{ Model } & \multicolumn{2}{|c|}{$\begin{array}{l}\text { Unstandarized } \\
\text { coefficients }\end{array}$} & \multicolumn{2}{|c|}{$\begin{array}{l}\text { Unstandarized } \\
\text { coefficients }\end{array}$} & \multirow{2}{*}{$\begin{array}{c}\text { Signifi- } \\
\text { cance } \\
(p)\end{array}$} & \multicolumn{2}{|c|}{$\begin{array}{l}95 \% \text { Confidence } \\
\text { interval for } \beta\end{array}$} \\
\hline & $\beta$ & $\begin{array}{l}\text { Standard } \\
\text { error }\end{array}$ & Beta & $t$ & & $\begin{array}{l}\text { Lower } \\
\text { bound }\end{array}$ & $\begin{array}{l}\text { Upper } \\
\text { bound }\end{array}$ \\
\hline Constant & 28.047 & 7.643 & & 3.670 & $=0.001$ & 12.759 & 43.334 \\
\hline Gender & -0.718 & 1.149 & -0.063 & -0.625 & $=0.534$ & -3.016 & 1.579 \\
\hline $\mathrm{VO}_{2}$ max & 0.102 & 0.048 & 0.204 & 2.137 & $=0.037$ & 0.007 & 0.198 \\
\hline SBP & -0.064 & 0.031 & -0.207 & -2.074 & $=0.042$ & -0.126 & -0.002 \\
\hline Optimism & 0.852 & 0.225 & 0.390 & 3.785 & $<0.001$ & 0.402 & 1.302 \\
\hline Pessimism & -0.828 & 0.242 & -0367 & -3.417 & $=0.001$ & -1.312 & -0.343 \\
\hline
\end{tabular}

Note: SBP = Systolic Blood Pressure

Relying on the current criteria [48] for Stage 2 hypertension, based on values of $\geq 90 \mathrm{mmHg}$ for diastolic and $\geq 140 \mathrm{mmHg}$ for systolic blood pressure, more than two-thirds of the current sample $(n=46)$ fall into this category. Employing a bootstrapped (1000 samples, 95\% confidence interval) multivariate analyses of covariance (MANCOVA) including gender and age as covariates, we tested whether people with Stage 2 hypertension differed in $\mathrm{VO}_{2}$ max, optimism, pessimism, and satisfaction with life from those exhibiting lower blood pressures $(<140 / 90 \mathrm{mmHg})$. The MANCOVA yielded a statistically significant multivariate effect for blood pressure groups (Wilks' $\lambda=0.852, F(4,59)=2.56, p=0.048$ ). The covariates were statistically not significant. The univariate tests revealed 
that only satisfaction with life differed statistically significantly $(F(1,62)=7.59$, $p=0.008$, effect size (corrected for sample size) Hedges' $g=0.752$ ) between those exhibiting Stage 2 hypertension versus those with lower blood pressure readings (Table 3 ).

We used the cut off values of 140/90 mmHg; its lower values are suggested to reflect normal, elevated or even Stage 1 hypertension according to the most recent classification suggested by the American College of Cardiology/American Heart Association Task Force [48]. Therefore, we performed another test from which we have excluded those with Stage 1 hypertension (i.e. systolic blood pressure between 130-139 $\mathrm{mmHg}$ and/or diastolic blood pressure between 80-89 $\mathrm{mmHg}$ ). This test confirmed our original findings that people exhibiting Stage 2 hypertension report lover $(M=24.64 \pm 4.06)$ satisfaction with life than those exhibiting either normal (i.e., $<120 \mathrm{mmHg}$ and $<80 \mathrm{mmHg}$ ), or elevated (i.e., $120-129 \mathrm{mmHg}$ and $<80 \mathrm{mmHg})$ blood pressures $(M=28.60 \pm 5.77)$. The mean differences were statistically significant $(F(1,54)=4.20, p=045$, effect size corrected for sample size (Hedges' $g$ ) $=0.71$ ).

Table 3. Means and standard deviations (in parenthesis) of four dependent measures in normotensive and hypertensive groups, the $\mathrm{F}$ and $\mathrm{p}$ values of the univariate tests, and the corrected effect sizes. Statistically significant group differences were only noted in the subjectively reported satisfaction with life

\begin{tabular}{lccccc} 
& $\begin{array}{c}\text { Normal, elevated } \\
\text { and Stage 1 } \\
\text { hypertensives } \\
(<140 / 90 \mathrm{mmHg}) \\
\mathrm{n}=22\end{array}$ & $\begin{array}{c}\text { Stage 2 } \\
\text { hypertensives } \\
\left(\begin{array}{l}2140 / 90 \mathrm{mmHg}) \\
\mathrm{n}=46\end{array}\right.\end{array}$ & $F$ & $p$ & $\begin{array}{c}\text { Effect size } \\
\text { Hedges' } g\end{array}$ \\
\hline $\mathrm{VO}_{2} \mathrm{max}(\mathrm{ml} / \mathrm{kg} / \mathrm{min})$ & $37.65(9.17)$ & $33.65(12.12)$ & 2.15 & .148 & 0.350 \\
Optimism & $12.10(2.83)$ & $11.33(2.50)$ & 1.25 & .267 & 0.036 \\
Pessimism & $5.76(2.30)$ & $6.38(2.63)$ & 0.01 & .935 & 0.242 \\
Satisfaction with life & $28.62(4.54)$ & $24.51(5.75)$ & 7.59 & $.008 *$ & 0.752 \\
\hline
\end{tabular}

Note: Statistically significant difference between the two means.

\section{DISCUSSION}

\section{PREDICTING POWER OF FOUR VARIABLES ON LIFE SATISFACTION}

This research suggests that almost half $(46 \%)$ of the total variance in life satisfaction is predicted by two indices of cardiovascular health, estimated aerobic fitness and systolic blood pressure, along with the psychological constructs of optimism and pessimism. These findings support the connection between positive emotions and cardiovascular indices and agree with the earlier reports in the literature disclosing a relationship between optimism and pessimism and life satisfaction [7, 21-24]. The direction of the relationship matches that reported by Szcześniak and Soares [7] in that optimism was directly, while pessimism was reversely associated with the reported satisfaction with life.

\section{NEW SUPPORT FOR THE CONNECTION BETWEEN BLOOD PRESSURE AND LIFE SATISFACTION}

The current results expand earlier findings concerning the relationship between blood pressure and satisfaction with life, because the only previously found study was conducted with children and adolescents [27], in contrast to the current research with middle-aged adults. In accord with Romero Martinez et al. [27], 
we also found an inverse relationship between blood pressure and satisfaction with life. However, expanding the results of the earlier study, which did not report separately systolic and diastolic blood pressure, the present findings suggest that while systolic blood pressure could be inversely associated with life satisfaction, the diastolic blood pressure appears to be uncorrelated with the latter.

The positive relationship between cardiorespiratory fitness and satisfaction with life, which was earlier demonstrated in studies children and/or adolescents $[4,31,32]$, was also demonstrated in the current work with middle aged adults. However, the present results are in contrast with a work conducted with university students in which estimated aerobic fitness was unrelated to the reported level of life satisfaction [33]. The incongruous findings may be attributed either to a low sample size used in that study, or to the very different nature of the sample studied. However, the latter explanation may be speculative, since the results of the present inquiry match those obtained with children and adolescents in three earlier studies.

Based on the beta ( $\beta$ ) values obtained in the regression (Table 2 ), the predictive power of the cardiovascular measures $\left(\mathrm{VO}_{2}\right.$ max and systolic blood pressure) was notably weaker than that of the psychological indices. Nevertheless, they contributed statistically significantly to the regression model and their predictive power might be higher in a larger sample, which could be the subject of future research. Until then, these preliminary findings offer support for the hypothesis of the study that satisfaction with life is associated with both mental attitudes and indices of cardiovascular health.

\section{LIFE SATISFACTION AND BLOOD PRESSURE STATUS}

Despite the modest contribution of the physiological measures, people classified into Stage 2 hypertension exhibited lower satisfaction with life, while they did not differ on other three dependent measures from those with lower blood pressure readings. The classification using the 140/90 $\mathrm{mmHg}$ cut-off value was made based on past classifications and still used in research practices [49], which consider lower values (i.e. Stage 1 hypertension, elevated blood pressure and normal blood pressure) to be in the normotensive range. This classification was necessary, because of the low number of individuals having blood pressure under the cut-off value $(\mathrm{n}=22)$. Nevertheless, eliminating 12 individuals in Stage 1 hypertension yielded the same results. Notable is the finding that the effect sizes corrected for the sample size were relatively large. Therefore, the new finding that Stage 2 hypertension may be linked to lower life satisfaction appears to be robust. However, no directionality could be established from the current data. The findings call for systematic investigation of directionality, since it is more likely that an unsatisfying life leads to elevated blood pressure than vice versa, but a vicious circle-mechanism may not be excluded.

The current findings are in accord with the results of a study implementing a 4-week rehabilitative exercise intervention with cardiac patients who showed greater aerobic capacity as well as lower blood pressure after the rehabilitation program than a control group [50]. Moreover, the exercise rehabilitation resulted in greater subjectively, as well as objectively, assessed quality of life in the participants who underwent the 4-week rehabilitative program versus those who did not. From these results, one may speculate that the direction of the relationship between cardiac health, as well as blood pressure status, and the quality of life (which could be expected to surface in one's satisfaction 
with life) could be health driven. Accordingly, a positive change in health status may be associated with greater satisfaction with life via a better life quality. While the results reported by Gierat-Haponiuk et al. [50] are supportive of this argument, we cannot rule out the conjecture that an opposite argument is also true. For example, a person constantly dissatisfied with life may develop psychosomatic symptoms, such as high blood pressure, in the long term. Therefore, research attention to both directions of the possible relationship between blood pressure status and satisfaction with life seems to be warranted.

\section{LIMITATIONS}

The current study is not without limitations. One concern revolves around the convenience sample represented by adults who could afford private health screening and cared for their health by voluntarily showing up and paying a fee for a cardiovascular health screening test. Another limitation is the on-site reading and averaging of blood pressure, which although is routinely done in research practice, is not as accurate as in prolonged ambulatory monitoring. Further, the estimation of the aerobic fitness is not as accurate as its direct measurement, even though the YMCA test has high concordance with the direct assessment of cardiorespiratory fitness [38]. These limitations should be taken into consideration when interpreting the findings, which should be appraised as preliminary, but sufficiently robust to stimulate more systematic work in this area. Future studies should also measure perceived stress and examine a more representative sample in testing the association between cardiovascular measures and positive emotions in their relevance to the response-shift and quality of life model [35].

\section{CONCLUSIONS}

In conclusion, the new findings emerging from this study are summarized as follows:

1. The association between aerobic fitness and life satisfaction, earlier noted only in children, also exists in adults.

2. The relationship between blood pressure and life satisfaction, earlier reported only in children, can also be observed in adults.

3. The systolic blood pressure has a stronger link to life satisfaction than the diastolic blood pressure.

4. There is strong evidence that people with Stage 2 hypertension experience less satisfaction with life than those with lower readings.

5. Optimism and pessimism are stronger predictors of the satisfaction with life than aerobic fitness and blood pressure.

\section{ACKNOWLEDGEMENTS}

We wish to thank the Corvin Medical Centre in Budapest, Hungary for its help in recruiting the participants and for providing permission to carry out the research in its private medical facilities.

\section{REFERENCES}

[1] Siahpush M, Spittal M, Singh GK. Happiness and life satisfaction prospectively predict self-rated health, physical health, and the presence of limiting, long-term health conditions. Am J Health Promot. 2008 Oct;23(1):18-26. https://doi.org/10.4278/ajhp.061023137

[2] St John PD, Mackenzie C, Menec V. Does life satisfaction predict five-year mortality in community-living older adults? Aging Ment Health. 2015;19(4):363-70. https://doi.org/10.1080/13607863.2014.938602

[3] Cornelissen VA, Fagard RH. Effects of endurance training on blood pressure, blood pressure-regulating mechanisms, and cardiovascular risk factors. Hypertension. 2005 Oct;46(4):667-75. https://doi. org/10.1161/01.HYP.0000184225.05629.51 
[4] Grao-Cruces A, Fernández-Martínez A, Nuviala A. Association of fitness with life satisfaction, health risk behaviors, and adherence to the Mediterranean diet in Spanish adolescents. J Strength Cond Res. 2014;28(8):2164-72. https://doi.org/10.1519/JSC.0000000000000363

[5] Peterson C, Park N, Seligman MEP. Orientations to happiness and life satisfaction: the full life versus the empty life. J Happiness Stud. 2005 Mar 1;6(1):25-41. https://doi.org/10.1007/s10902-004-1278-z

[6] Yalçın İ. Social Support and Optimism as Predictors of Life Satisfaction of College Students. Int J Advance Counsel. 2011;33(2):79-87. https://doi.org/10.1007/s10447-011-9113-9

[7] Szcześniak M, Soares E. Are proneness to forgive, optimism and gratitude associated with life satisfaction? Polish Psychol Bull. 2011;42(1):20-3. https://doi.org/10.2478/v10059-011-0004-z

[8] Carver CS, Scheier MF, Segerstrom SC. Optimism. Clin Psychol Rev. 2010;30(7):879-89. https://doi. org/10.1016/j.cpr.2010.01.006

[9] Boehm JK, Peterson C, Kivimaki M, Kubzansky L. A prospective study of positive psychological wellbeing and coronary heart disease. Health Psychol. 2011 May;30(3):259-67. https://doi.org/10.1037/ a0023124

[10] Kubzansky LD, Sparrow D, Vokonas P, Kawachi I. Is the glass half empty or half full? A prospective study of optimism and coronary heart disease in the normative aging study. Psychosom Med. 2001;63(6):910-916. https://doi.org/10.1097/00006842-200111000-00009

[11] Scheier MF, Matthews KA, Owens JF, et al. Dispositional optimism and recovery from coronary artery bypass surgery: the beneficial effects on physical and psychological well-being. J Pers Soc Psychol. 1989;57(6):1024-40. https://doi.org/10.1037/0022-3514.57.6.1024

[12] Ronaldson A, Molloy GJ, Wikman A, Poole L, Kaski J-C, Steptoe A. Optimism and recovery after acute coronary syndrome: A clinical cohort study. Psychosom Med. 2015 Apr;77(3):311-8. https://doi. org/10.1097/PSY.0000000000000155

[13] Giltay EJ, Geleijnse JM, Zitman FG, Hoekstra T, Schouten EG. Dispositional optimism and all-cause and cardiovascular mortality in a prospective cohort of elderly dutch men and women. Arch Gen Psychiatry. 2004;61(11):1126-35. https://doi.org/10.1001/archpsyc.61.11.1126

[14] Giltay EJ, Kamphuis MH, Kalmijn S, Zitman FG, Kromhout D. Dispositional optimism and the risk of cardiovascular death: the Zutphen Elderly Study. Arch Intern Med. 2006 Feb 27;166(4):431-6. https://doi.org/10.1001/.431

[15] Tindle HA, Chang Y-F, Kuller LH, et al. Optimism, cynical hostility, and incident coronary heart disease and mortality in the women's health initiative. Circulation. 2009 Aug 25;120(8):656-62. https://doi. org/10.1161/CIRCULATIONAHA.108.827642

[16] Boehm JK, Kubzansky LD. The heart's content: the association between positive psychological wellbeing and cardiovascular health. Psychol Bull. 2012 Jul;138(4):655-91. https://doi.org/10.1037/ a0027448

[17] Serlachius A, Pulkki-Råback L, Elovainio M, et al. Is dispositional optimism or dispositional pessimism predictive of ideal cardiovascular health? The Young Finns Study. Psychol Health. 2015;30(10):122139. https://doi.org/10.1080/08870446.2015.1041394

[18] Nabi H, Koskenvuo M, Singh-Manoux A, et al. Low pessimism protects against stroke: the Health and Social Support (HeSSup) prospective cohort study. Stroke. 2010;41(1):187-90. https://doi. org/10.1161/STROKEAHA.109.565440

[19] Mahler HIM, Kulik JA. Optimism, pessimism and recovery from coronary bypass surgery: Prediction of affect, pain and functional status. Psychol Health Med. 2000 1;5(4):347-58. https://doi. org/10.1080/713690216

[20] Scheier MF, Carver CS. Optimism, coping, and health: Assessment and implications of generalized outcome expectancies. Health Psychol. 1985;4(3):219-47. https://doi.org/10.1037/0278-6133.4.3.219

[21] Bailey TC, Eng W, Frisch MB, Snyder CR. Hope and optimism as related to life satisfaction. J Positive Psychol. 2007;2(3):168-75. https://doi.org/10.1080/17439760701409546

[22] Chang EC, Maydeu-Olivares A, D’Zurilla TJ. Optimism and pessimism as partially independent constructs: Relationship to positive and negative affectivity and psychological well-being. Personal Individ Differ. 1997 Sep 1;23(3):433-40. https://doi.org/10.1016/S0191-8869(97)80009-8

[23] Chang EC, Sanna LJ. Optimism, pessimism, and positive and negative affectivity in middle-aged adults: A test of a cognitive-affective model of psychological adjustment. Psychology and Aging. 2001;16(3):524-31. https://doi.org/10.1037/0882-7974.16.3.524

[24] Liberman V, Boehm JK, Lyubomirsky S, Ross LD. Happiness and memory: affective significance of endowment and contrast. Emotion. 2009;9(5):666-680. https://doi.org/10.1037/a0016816

[25] Boehm JK, Peterson C, Kivimaki M, Kubzansky L. Heart health when life is satisfying: evidence from the Whitehall II cohort study. Eur Heart J. 2011 Nov;32(21):2672-7. https://doi.org/10.1093/ eurheartj/ehr203

[26] Einvik G, Ekeberg O, Klemsdal TO, Sandvik L, Hjerkinn EM. Physical distress is associated with cardiovascular events in a high risk population of elderly men. BMC Cardiovasc Disord. 2009 Mar 30;9:14. https://doi.org/10.1186/1471-2261-9-14

[27] Romero Martinez V, Silva E, Villasmil JJ. Relationship between life satisfaction levels and high blood pressure in adolescents. J Hypertension. 2010 Jun;28:e260. https://doi.org/10.1097/01. hjh.0000378969.24759.c5

[28] Holt-Lunstad J, Birmingham W, Jones BQ. Is there something unique about marriage? The relative impact of marital status, relationship quality, and network social support on ambulatory blood pressure and mental health. Ann Behav Med. 2008 Apr;35(2):239-44. https://doi.org/10.1007/s12160008-9018-y

[29] Fujita F, Diener E. Life satisfaction set point: stability and change. J Pers Soc Psychol. 2005;88(1):15864. https://doi.org/10.1037/0022-3514.88.1.158 
[30] Schwerdtfeger A, Gaisbachgrabner K, Traunmüller C. Life satisfaction and hemodynamic reactivity to mental stress. Ann Behav Med. 2017 Jun;51(3):464-9. https://doi.org/10.1007/s12160-016-9858-9

[31] Marques A, Mota J, Gaspar T, de Matos MG. Associations between self-reported fitness and self-rated health, life-satisfaction and health-related quality of life among adolescents. J Exerc SciFitness. 2017 Jun 1;15(1):8-11. https://doi.org/10.1016/j.jesf.2017.03.001

[32] Padilla-Moledo C, Castro-Piñero J, Ortega FB, et al. Positive health, cardiorespiratory fitness and fatness in children and adolescents. Eur J Public Health. 2012 Feb;22(1):52-6. https://doi.org/10.1093/ eurpub/ckr005

[33] Busing K, West C. Determining the relationship between physical fitness, gender, and life satisfaction. SAGE Open. 2016 Oct 1;6(4):2158244016669974. https://doi.org/10.1177/2158244016669974

[34] Craig CL, Shields M, Leblanc AG, Tremblay MS. Trends in aerobic fitness among Canadians, 1981 to 2007-2009. Appl Physiol Nutr Metab. 2012 Jun;37(3):511-9. https://doi.org/10.1139/h2012-023

[35] Sprangers MA, Schwartz CE. Integrating response shift into health-related quality of life research: A theoretical model. Soc Sci Med. 1999 Jun;48(11):1507-15. https://doi.org/10.1016/S02779536(99)00045-3

[36] World Medical Association. World Medical Association Declaration of Helsinki: Ethical Principles for Medical Research Involving Human Subjects. JAMA. 2013 Nov 27;310(20):2191-4. https://doi. org/10.1001/jama.2013.281053

[37] Faul F, Erdfelder E, Lang A-G, Buchner A. G*Power 3: A flexible statistical power analysis program for the social, behavioral, and biomedical sciences. Behav Res Methods. 2007 May;39(2):175-91. https://doi.org/10.3758/BF03193146

[38] Beekley MD, Brechue WF, Dehoyos DV, Garzarella L, Werber-Zion G, Pollock ML. Cross-validation of the YMCA submaximal cycle ergometer test to predict VO2max. Res Q Exerc Sport. 2004 Sep 1;75(3):337-42. https://doi.org/10.1080/02701367.2004.10609165

[39] Cuckson AC, Reinders A, Shabeeh H, Shennan AH, British Hypertension Society. Validation of the Microlife BP 3BTO-A oscillometric blood pressure monitoring device according to a modified British Hypertension Society protocol. Blood Press Monit. 2002;7(6):319-24. https://doi. org/10.1097/00126097-200212000-00005

[40] Diener E, Emmons RA, Larsen RJ, Griffin S. The Satisfaction With Life Scale. J Pers Assess. 1985 Feb;49(1):71-5. https://doi.org/10.1207/s15327752jpa4901 13

[41] Pavot W, Diener E. Review of the Satisfaction With Life Scale. Psychol Assess. 1993;5(2):164-72. https://doi.org/10.1037/1040-3590.5.2.164

[42] Pavot W, Diener E. The Satisfaction With Life Scale and the emerging construct of life satisfaction. J Positive Psychol. 2008;3(2):137-52. https://doi.org/10.1080/17439760701756946

[43] Martos T, Sallay V, Désfalvi J, Szabó T, Ittzés A. Az Élettel való Elégedettség Skála magyar változatának (SWLS-H) pszichometriai jellemzői = Psychometric characteristics of the Hungarian version of the Satisfaction with Life Scale (SWLS-H) [Psychometric characteristics of the Hungarian version of the Satisfaction with Life Scale (SWLS-H)]. Mentálhigiéné és Pszichoszomatika. 2014;15:289-303. Hungarian. https://doi.org/10.1556/Mental.15.2014.3.9

[44] Bérdi M, Köteles F. Az optimizmus mérése: az Életszemlélet Teszt átdolgozott változatának (LOT-R) pszichometriai jellemzői hazai mintán [Measuring optimism: psychometric characteristics of the revised version of the Life Attitude Test (LOT - R) in a Hungarian sample]. Magyar Pszichológiai Szemle. 2010 Jun;65(2):273-94. Hungarian.

[45] Scheier MF, Carver CS, Bridges MW. Distinguishing optimism from neuroticism (and trait anxiety, self-mastery, and self-esteem): A reevaluation of the Life Orientation Test. J Personal Soc Psychol. 1994;67(6):1063-78. https://doi.org/10.1037/0022-3514.67.6.1063

[46] Herzberg PY, Glaesmer H, Hoyer J. Separating optimism and pessimism: a robust psychometric analysis of the revised Life Orientation Test (LOT-R). Psychol Assess. 2006;18(4):433-8. https://doi. org/10.1037/1040-3590.18.4.433

[47] Lehtonen AO, Langén VL, Porthan K, et al. Electrocardiographic predictors of atrial fibrillation in nonhypertensive and hypertensive individuals. J Hypertens. 2018;36(9):1874-81. https://doi. org/10.1097/HJH.0000000000001760

[48] Whelton PK, Carey RM, Aronow WS, et al. 2017 ACC/AHA/AAPA/ABC/ACPM/AGS/APhA/ASH/ASPC/ NMA/PCNA guideline for the prevention, detection, evaluation, and management of high blood pressure in adults: A report of the American College of Cardiology/American Heart Association Task Force on clinical practice guidelines. Hypertension. 2018 Jun 1;71(6):e13-115. https://doi. org/10.1161/HYP.0000000000000076

[49] Youngstrom M, Tita A, Grant J, Szychowski JM, Harper LM. Perinatal outcomes in women with a history of chronic hypertension but normal blood pressures before 20 weeks of gestation. Obstet Gynecol. 2018;131(5):827-34. https://doi.org/10.1097/AOG.0000000000002574

[50] Gierat-Haponiuk K, Haponiuk I, Szalewska D, et al. Effect of complex cardiac rehabilitation on physical activity and quality of life during long-term follow-up after surgical correction of congenital heart disease. Kardiol Pol. 2015;73(4):267-73. https://doi.org/10.5603/KP.a2014.0206 